\title{
O USO DA AROMATERAPIA NO COMBATE AO ESTRESSE ${ }^{1}$
}

\author{
Tatiana Paganini ${ }^{2}$ \\ Yolanda Flores e Silva
}

PAGANINI, T.; FLORES e SILVA, Y. O uso da aromaterapia no combate ao estresse. Arq. Ciênc. Saúde Unipar, Umuarama, v. 18 n. 1 , p. 43-49, jan./abr. 2014

\begin{abstract}
RESUMO: O modelo biomédico tradicional, muitas vezes, realiza o atendimento fragmentado, não dá ênfase ao ser humano em sua totalidade. A correria do dia a dia faz com que o homem fique mais vulnerável aos agentes estressores, desestabilizando seu organismo. Por isso, há necessidade do atendimento acolhedor e humanitário por meio do cuidado integral, promovendo o bem-estar e qualidade de vida. As terapias complementares como a aromaterapia vem ganhando grande destaque nas áreas da estética e saúde. Essas terapias, segundo referenciais como os de Helman (2004), conseguem muitas vezes proporcionar para as pessoas que utilizam a sensação de equilíbrio corpóreo e bem-estar entre outros aspectos pessoais / individuais. Vários óleos essenciais são utilizados para o tratamento do estresse e devem ser manipulados por um profissional com conhecimento científico sobre os efeitos que proporciona. O objetivo do presente trabalho, consiste em uma levantamento bibliográfico da utilização dos óleos essenciais no tratamento do estresse, bem como em suas consequências a para a saúde. Conclui-se que a aromaterapia possui um papel significativo nos efeitos do estresse, pois proporciona momentos de satisfação e bem estar ao paciente.
\end{abstract}

PALAVRAS-CHAVE: Humanização; Estresse; Cuidado integral; Aromaterapia; Óleos essenciais.

\section{USE OF AROMATHERAPY IN THE FIGHT AGAINST STRESS}

ABSTRACT: The traditional biomedical model often provides a fragmented care, not emphasizing the human being in its entirety. The everyday rush makes humans become more vulnerable to stressors, destabilizing their body. Thus, there is the need for warm and humanitarian assistance through comprehensive care, promoting well-being and quality of life. Complementary therapies such as aromatherapy have gained great prominence in the fields of aesthetics and health. These therapies, according to references such as Helman (2004), can often provide the sensation of balance and well-being, among other personal/individual aspects. Various essential oils are used for treating stress and should be handled by a professional with scientific knowledge on the effects they provide. The aim of this work consists in a literature review on the use of essential oils in the treatment of stress and its consequences in terms of health. It can be concluded that aromatherapy has a significant role in the effects of stress as it provides moments of satisfaction and well-being to the patient.

KEYWORDS: Humanization; Stress; Comprehensive care; Aromatherapy; Essential oils.

\section{Introdução}

O estresse é uma das doenças que mais atingem as pessoas nos últimos tempos, consegue desestabilizar o ser humano no seu equilíbrio corpóreo e traz muitas consequências físicas e psicológicas para o organismo. Segundo (SADIR; BIGNOTTO; LIPP, 2010), o estresse atinge as pessoas no nível biológico como a dificuldade de relações interpessoais, depressão, ansiedade, infelicidade o que gera consequências destruidoras.

Quando o indivíduo com o estresse procura um tratamento, é perceptível que ainda o modelo biomédico tradicional não permite um acolhimento profundo do paciente, pois o ser humano não é visto como um ser único acaba então tornando o seu atendimento fragmentado e sem perspectiva de um todo. Mesmo que a promoção da saúde tenha por objetivo a integralidade, o fortalecimento das relações do paciente e do profissional da saúde, muito ainda se vê da necessidade do processo saúde-doença ser acolhedor, dinâmico e fortalecedor para o indivíduo doente (LIMA; OLIVEIRA, 2012).

A doença quando é acometida, destrói a saúde não somente física, associada a fatores biológicos, mas atinge os fatores psicológicos que são relacionados a nosso estado emocional, essa questão reflete em todo o organismo do ser humano e traz consequências maléficas para o corpo.

Por conta de toda a fragilidade do sistema, as terapias complementares vêm ganhando um grande destaque como o coadjuvante nos tratamentos convencionais, isso porque são tratamentos não invasivos e proporcionam bem estar ao paciente, colaborando significadamente para estas questões (TSUCHIYA; NASCIMENTO, 2002).

Nas terapias complementares o paciente é tratado em sua totalidade, da mente, do corpo e espírito, no seu âmbito biopsicoespiritual, neste momento o paciente deixa de ser encarado como vítima para ser tratado como agente ativo e complementar ao trabalho da equipe de saúde. Por isso há um grande avanço dessas terapias, pois auxiliam positivamente no enfretamento da doença, como o estresse em questão (BONTEMPO, 2001).

Quando se fala sobre terapias complementares, têm um grande destaque a técnica de Aromaterapia que são a utilização de óleos essenciais para estabelecer o equilíbrio da mente e dos sistemas do corpo, ocasionando um bem estar e consequentemente promovendo uma melhor qualidade de vida para as pessoas afetadas pelo estresse (TROVO; SILVA; LEÃO, 2003).

Objetivo geral foi apresentar em produções documentais e bibliográficas o uso da aromaterapia e sua contribuição no cuidado às pessoas com estresse, os objetivos

DOI: https://doi.org/10.25110/arqsaude.v18i1.2014.5157

${ }^{1}$ Este artigo é parte da dissertação da mestranda, do Programa do Mestrado Profissional em Saúde e Gestão do trabalho, da Universidade do Vale do Itajaí, $\mathrm{SC}$.

${ }^{2}$ Mestranda do Curso de Mestrado Profissional de Saúde e Gestão do Trabalho, Tecnóloga em Cosmetologia e Estética, Professora da disciplina de Cosmética e Estética dos Anexos Cutâneos do Curso Superior em Tecnologia em Cosmetologia e Estética da Univesidade do Vale do Itajaí, SC. E-mail: tatiana_paganini@univali.br - Fone (47) 9946-0302 - Rua Jesuino Anastacio Pereira, n. 60, Camboriu, SC

${ }^{3}$ Professor, a, Dra. do Curso de Mestrado Profissional de Saúde e Gestão do Trabalho da Universidade do Vale do Itajaí, SC. E-mail: yolanda@univali.br 
específicos foram analisar as fichas dos óleos essenciais utilizados no combate da patologia do estresse, verificar seu uso, ações e efeitos da aromaterapia para o organismo.

\section{Desenvolvimento}

Para a elaboração do estudo utilizou-se da revisão de literatura sobre os temas de promoção da saúde, humanização, cuidado integral, estresse, bem estar, qualidade de vida e as terapias complementares como a aromaterapia. Para a construção do trabalho, a busca dos materiais científicos foi realizada por meio de livros, dissertações e artigos científicos na plataforma Scielo.

\section{Promoção da saúde}

O modelo biomédico não atende mais totalmente às necessidades de saúde da sociedade (MASCARENHAS, 2005), por conta disso surge no final do século XX a promoção de saúde como estratégia para um novo modelo.

O conceito de Promoção foi amplamente discutido na Primeira Conferência Internacional de Promoção de Saúde em Ottawa em 1986, originando a carta de Ottawa, na qual postulou a ideia da saúde como qualidade de vida resultante do complexo processo que é condicionante por vários fatores, como alimentação, justiça, ecossistema entre outros (CZERESNIA, 2003).

Segundo o Ministério da Saúde, o direito da saúde significa a garantia, pelo Estado, de condições dignas de vida e de acesso universal e igualitário às ações e serviços de promoção, proteção e recuperação da saúde, em todos os seus níveis, a todos os habitantes do território nacional, levando ao desenvolvimento pleno do ser humano em sua individualidade. (BRASIL, 1986).

No entanto, quando nos referimos à saúde estamos lidando com algo tão amplo como a própria noção de vida. É envolvida não somente pelas ações do âmbito do Estado como a própria autonomia dos sujeitos.

A promoção da saúde envolve o fortalecimento da capacidade individual e coletiva para lidar com a multiplicidade dos condicionantes da saúde. Santos (1987), argumenta que buscar saúde é questão não só de sobrevivência, mas de qualificação da existência. É remitido pela dimensão social, existencial e ética.

A promoção de saúde é mencionada como um nível de atenção da medicina preventiva, correspondente à prevenção primária, que consta de medidas destinadas ao desenvolvimento de uma saúde melhor (BUSS, 2000).

No Brasil, infelizmente mesmo com as contínuas reformas do final do século XX, as políticas públicas permanecem conservadoras e carentes de recursos. Com a estratégia de promoção de saúde esperava-se que o próprio sistema tivesse um olhar mais humano, social, técnico e humanizado sobre todo o processo de saúde-doença relacionado à qualidade de vida de acordo com Mascarenhas (2005).

\section{Humanização em saúde}

O desejo de humanizar, de garantir que tudo que envolva a saúde e a doença das pessoas seja digno da condição humana, converteu-se em um anseio universal. Humanizar não é uma tarefa exclusiva da saúde; afeta da mesma forma a cultura, a política, a educação, a economia. Em todos os âmbitos em que o ser humano se realiza ou atua.

A questão central da humanização é fazer a relação dos profissionais da saúde, os quais possuem conhecimentos específicos, e do paciente, que está fragilizado, angustiado uma experiência saudável, afetiva e acolhedora (BERMEJO, 2008).

Humanizar está diretamente interligado por alcançarmos aquilo que ainda não conseguimos, é o olhar atento, o carinho, a atenção, a solidariedade com o próximo. É saber acima de tudo, repensar a maneira da intervenção no momento do diagnóstico e assim esquematizar o tratamento e a forma que o profissional vai auxiliar no processo saúde-doença.

Quando há o trabalho humanizado, todas as pessoas envolvidas são beneficiadas, pois há uma melhor qualidade de vida para os doentes e para os profissionais da saúde. $\mathrm{O}$ indivíduo consegue responder melhor ao enfrentamento da doença, como o estresse e a relação se torna mais produtiva, o paciente então, não se torna apenas um número, mas sim como o sujeito ativo desta relação.

\section{Estresse}

O estresse é um dos fatores que mais atingem as pessoas, seja por mudanças nos estilos de vida ou por fatores que as pessoas não conseguem enfrentar. Isso os torna cada vez mais vulneráveis, debilitando diretamente em seu corpo.

De acordo com Lipp (2001), o estresse é definido como uma tensão e como consequência há um desequilíbrio corpóreo, uma doença no próprio organismo, desestabilizando e ocasionando os malefícios.

Quando o ser humano não permite se adaptar com os fatores do seu dia a dia pode neste momento estar mais vulnerável aos agentes estressores, enfraquecendo seu estado físico, relacionado aos fatores biológicos, e ao seu estado psicológico relacionado diretamente aos fatores emocionais, sendo que o emocional é um fator extremamente importante para a qualidade de vida, é necessário sempre ter o equilíbrio para assim obter o bem estar.

A própria globalização e o mercado competitivo tornaram-se coadjuvantes para a obtenção do estresse, segundo Lipp (2011, p. 348):

As mudanças ocorridas na sociedade moderna são marcantes. Elas são excitantes, frenéticas e, muitas vezes, rápidas demais para permitirem ao homem uma absorção do seu ritmo e do seu significado. A competição excessiva, o desejo intenso de "possuir", a pressa, o medo do outro ser humano, a pressão diária que as pessoas bem-sucedidas se impõem inegavelmente afetam sua qualidade de vida. Desse modo, a qualidade de vida é prejudicada, pois uma vida de insegurança e incerteza necessariamente fica aquém do que se almeja como uma vida de boa qualidade.

É válido lembrar que nem todas as pessoas serão afetadas pelos mesmos fatores estressantes, isso se dá através do seu ambiente familiar, cultura e crença. O estresse quando é dominado no ser humano compromete a saúde e pode ainda estar desenvolvendo outras doenças.

Segundo Sadir; Bignotto; Lipp (2010) o estresse ocupacional é quando há um grande desgaste no organismo 
do ser humano e interfere paralelamente em sua produtividade no ambiente de trabalho.

No caso do Brasil, como o mercado está em desenvolvimento, o índice de pessoas estressadas está cada vez mais se elevando, os profissionais que estão diretamente relacionados ao estresse ocupacional são executivos de ambos os sexos, policiais militares, professores e bancários. É preciso fazer medidas de prevenção e ações que gerenciam a maneira de lidar com o estresse (LIPP, 2001). O tratamento ainda necessita ser mais amplo, totalitário e acolhedor promovendo assim o cuidado integral.

\section{Cuidado integral}

Para promover o cuidado integral é preciso que os profissionais da saúde adotem medidas igualitárias, afetivas e participativas com todos os membros envolvidos no processo, seja paciente, familiares e os próprios profissionais da saúde.

As medidas visam o acolhimento da pessoa fragilizada visando o melhor enfrentamento da doença, com atitudes de empatia, olhar atento, solidariedade e ética dos procedimentos envolvidos.

O cuidado compreende e inclui também o sentido de afeição, preocupação, assim como o de responsabilidade pelas pessoas necessitadas (DONAHUE, 1985).

Bermejo (2008) corrobora argumentando que reconhecer o outro é reconhecer um ser humano, pois atitudes como essas conseguem promover uma melhor qualidade de vida e bem estar ao paciente.

\section{Qualidade de vida e bem estar}

Com toda a correria do dia a dia muito tem se buscado obter qualidade de vida, pois com todos os agentes estressores que estão envolvidos em sua vida o homem se torna muito vulnerável para desenvolver o estresse.

Mas a terminologia da qualidade de vida vem sofrendo com o passar do tempo variadas modificações isso porque, a crença, a cultura e a própria criação são diferenciadas de pessoa para pessoa.

Segundo os autores Almeidas e Guiterrez (2004), a qualidade de vida é também atribuída aos fatores como o ambiente de trabalho, os amigos, a família além do próprio bem estar físico, mental e emocional.

A qualidade de vida está também associada ao bem estar, o ser humano necessita vivenciar momentos que proporcionam felicidade e alegria para obter uma vida saudável (SIQUEIRA; PADOVAN, 2008).

Momentos de satisfação para o ser humano muitas vezes não são compreendidos por toda a vida atribulada que vivencia, no entanto, quando há o diagnóstico da doença, muito valor se atribui a qualidade de vida associada a ao bem estar.

De acordo com Siqueira e Padovan (2008 apud RYAN; DECI, 2001), há duas abordagens sobre o bem estar, uma subjetiva de felicidade, chamada de bem estar hedônico, e outra que aborda o potencial humano, chamada de bem estar eudemônico, trata do bem estar psicológico. A visão hedônica associa o bem estar à felicidade e a eudomonica visa à capacidade do ser humano pensar e raciocinar.
O tratamento do estresse precisa ser contemplado na sua totalidade, como em muitas situações o modelo biomédico tradicional não consegue permitir todo o acolhimento para o paciente, às terapias complementares com a técnica de aromaterapia vêm auxiliando na intenção de trazer o bem estar físico, mental e espiritual para as pessoas fragilizadas.

\section{Terapias complementares}

As terapias complementares remetem a união, aproximação entre diferentes elementos. Os quais abrangem o corpo, a mente e o espírito além dos aspectos do estilo de vida.

É a proposta de uma mudança na perspectiva do adoecer e na recuperação da saúde, acontecendo uma transformação na atitude do indivíduo diante do processo e um fortalecimento da sua vida emocional.

O uso das terapias complementares no Brasil é adequado ao Sistema Único de Saúde (SUS) por meio da Portaria de $n^{\circ} 971$, que incentiva e regulamenta a adoção dessas técnicas nas unidades dos Estados, Municípios e Distrito Federal (BRASIL, 2006).

A aromaterapia é uma terapia complementar que visa reintegrar o equilíbrio corpóreo desestruturado pelo estresse. Faz o uso de óleos essenciais que são originados de plantas, caules, raízes ou flores cada qual com suas propriedades e atuam no organismo por completo. Os métodos para os efeitos dos óleos essenciais são a inalação ou a absorção pela pele e atuam farmacologicamente, fisiologicamente e psicologicamente no corpo (TSUCHIYA; NASCIMENTO, 2002).

A terminologia da Aromaterapia significa aroma cheiro e terapia a cura de acordo com (LASZLO, 2013). O termo teve sua grande repercussão com o químico René Maurice Gatefossé em 1964, na qual instintivamente queimou sua mão e colocou dentro de um vasilhame de lavanda, percebeu então os efeitos da cicatrização proeminente dos efeitos do óleo essencial de lavanda (KELLER, 2009).

Os óleos essenciais quando inalados são estimulados pelas células nervosas olfativas e ativam o sistema límbico, região do cérebro responsável pela olfação, memória e emoção e assim produzem os efeitos desejados dos óleos. Quando são ativados pelos poros da pele, através da massagem, sua via atravessa a corrente sanguínea ocasionando os efeitos então desejados (ANDREI; PERES; COMUNE, 2005).

A maioria dos óleos essenciais possuem grau de toxicidade alto quando utilizados puros, desencadeando alguma reação no organismo, por isto somente os óleos de lavanda (alfazema) e o melaleuca (tea-tree) podem ser usados puros, os outros óleos essenciais restantes possuem alta concentração e por conta desta situação são sempre diluídos em óleos carreadores (bases vegetais), precisam ainda ser conservados em embalagens âmbar e estar hermeticamente fechados, os óleos essenciais são extremamente voláteis assim evaporam com facilidade (DAVIS, 1996).

Há uma variedade de maneiras da sua utilização, os principais e mais utilizados de acordo com os autores (SILVA, 1998; SCHOTTEN; CORREA, 2010; ALVES; SILVEIRA; AMARAL, 2012; PRICE, 2006; LAVABRE, 2005) são: 
- Aromatização ambiental: na qual são colocadas gotas de óleos essenciais nos aromatizadores e ao evaporarem proporcionam os efeitos dos óleos na estimulação dos receptores olfativos.

- Pulverizadores: são utilizados diluídos, mistura-se $100 \mathrm{ml}$ de álcool $50 \%$ ou $50 \mathrm{ml}$ de álcool $96 \%$ e $50 \mathrm{ml}$ de água e colocar 10 gotas de óleo essencial em um recipiente spray de vidro âmbar, e assim promovem os efeitos desejados.

- Banhos aromáticos: os banhos ativam o sistema circulatório, regularizam o sistema nervoso, há dois tipos, os banhos de imersão que são aplicados na banheira com aproximadamente 10 gotas de óleos essenciais diluídos na gordura (nata) do leite e nos óleos vegetais, em água de $37^{\circ} \mathrm{C}$ e ficar no máximo 20 minutos, há também os banhos de assento promovem bem estar e assepsia, dilui-se em média de 6 a 8 gotas de óleos essenciais em uma colher de vodka, ou em $5 \mathrm{ml}$ de óleo vegetal e posterior em um copo de leite integral morno será dissolvida então em uma bacia de água quente.

- Compressas: frias ou quentes, as frias utilizadas em sinais de inflamação, situações agudas, coloca-se meio litro de água fria e 5 gotas de óleo essencial, embeber o tecido, tirar o excesso e aplicar sobre a pele, as compressas quentes utilizadas em situações crônicas, colocar meio litro de água fervente e 5 gotas de óleo essencial, embeber o tecido, tirar o excesso e repousar sobre a pele, deve trocar a compressa quando esfriar, pode ainda cobrir a compressa com um tecido de lã para evitar a perda de calor.

- Inalações: dois tipos, á seco para medos, coloca-se 3 gotas de óleo essencial em um lenço e depois inalar sem encostar o nariz, a inalação úmida é usada para gripes, resfriados, coloca-se de 4 a 10 gotas de óleo essencial em uma vasilha grande em um litro de água fervente, manter então os olhos fechados e cobrir a cabeça com uma toalha, fazer a inalação no máximo por dez minutos.

- Massagem; possui efeito calmante e relaxante, através do toque, utiliza-se 10 a $20 \mathrm{ml}$ de óleo vegetal e aproximadamente 8 gotas de óleo essencial, como a pele absorve rapidamente logo os efeitos dos óleos essenciais são percebidos.

- Pedilúvios: são conhecidos como escalda-pés, a pele dos pés absorve rapidamente os óleos essenciais, por isso são bastante utilizados, coloca-se 3 litros de água fervente e 10 gotas de óleo essencial em $5 \mathrm{ml}$ de óleo vegetal em um copo de leite integral, pode ainda colocar uma colher de sal grosso e proporcionar um melhor relaxamento, utilizados em dores de cabeça e problemas emocionais.

- Manilúvios: funciona para promover o relaxamento, ativa também o sistema circulatório e regulariza o sistema nervoso, com dois litros de água a $37^{\circ} \mathrm{C}$ e aproximadamente 7 gotas de óleo essencial em $5 \mathrm{ml}$ de óleo vegetal, em um copo de leite integral.

- Gargarejos e bochechos: tratam o mau hálito e inflamações, nos gargarejos tomar um gole de 2 a 5 gotas de óleo essencial em um copo de água, olhar para o teto e agitar o líquido da boca, o volume é de 15 a $25 \mathrm{ml}$, recomendados 3 gargarejos de acordo com a necessidade; nos bochechos são colocados $200 \mathrm{ml}$ de água potável e 20 gotas de óleo essencial conforme o tratamento, agitar a solução por 30 segundos e coar em um filtro de algodão cru, colocar então em uma garrafa de vidro esterilizado e fechar, consumir dentro de meio ano, os gargarejos e bochechos não devem ser ingeridos.

- Puros: apenas os óleos essenciais de lavanda (alfazema) e melaleuca (tea-tree) podem ser utilizados diretamente sobre a pele, sobre queimaduras e picadas de insetos.

- Oral: para a ingestão de óleos essenciais é de suma importância que tenha extrema qualidade terapêutica, foi submetido a testes toxicológicos, podem ser combinados com mel, nos casos de azie e ulceras e contra-indicado durante a gestação.

Para a obtenção dos óleos essenciais, há uma diversidade de maneiras para a sua extração como destilação, subdivididos em hidrodestilação, destilação por arraste de vapor, prensagem para os óleos essências cítricos e extração do solvente e eufloragem ou enfleurage além da extração por fluído supercrítico que quase não são mais utilizados, pois requer muita matéria prima vegetal e pouco óleo essencial, justificando os diferentes valores dos óleos essenciais (SIMÕES, 1999).

Conforme Silva (1998), o método de hidrodestilação contém a caldeira, onde fica as plantas que vão ser destiladas, um capitel que aguenta a pressão e uma serpentina refrigerada de cobre, que faz com que a água condense o vapor; a destilação com vapor d'água saturado à pressão atmosférica que contém um disco com perfuração no fundo da caldeira que separa a erva então da água, este método é um pouco mais elaborado que a hidrodestilação, pois permite a retificação do óleo essencial e a destilação a vácuo, utiliza então o vapor seco, usado por muitas indústrias, pois é rápido e econômico além de obter um óleo de melhor qualidade pois não há o contato da planta com a água.

Prensagem utilizada principalmente por óleos essenciais cítricos, as cascas das frutas ficam imersas por várias horas na água e depois é feita a extração, pode ser manualmente ou por máquinas.

Extração de solvente é um método que funciona com um extrator rotatório, tambores envolvidos por camisas de vapor, onde passa o vapor quente. Os tambores são divididos em compartimentos com placas perfuradas e assim neste compartimento são colocadas às flores para passar pelo processo de lavagem, as flores tratadas são imersas no solvente que obtêm o líquido que é o óleo essencial.

A eufloragem ou enfleurage é um método desenvolvido pelos franceses, coloca-se uma camada de pétalas sobre banha ou gordura depurada que repousa sobre uma placa de vidro, o processo é repetido, e pode demorar de 3 a 10 se- 
manas.

Extração por fluído supercrítico apresenta como um fator o seu meio de extração ser um gás, com grande densidade e por isso a extração para a obtenção dos óleos essenciais são muito mais intensas (MAUL; WASICKY; BACCHI, 1996).

\section{Óleos essenciais no estresse}

Os óleos essenciais quando utilizados por um profissional com conhecimento e aplicados com métodos e dosagem correta permitem o equilíbrio do organismo nas dimensões físicas, mentais e espirituais, sempre é válido lembrar que para os efeitos desejados é necessário à utilização de óleos essenciais com qualidade.

O estresse afeta o organismo do ser humano e provocam desequilíbrios, a aromaterapia consegue proporcionar uma melhora significativa nesta patologia, diminuindo os efeitos ocasionados no corpo humano.

Os óleos essenciais mais recomendados para o estresse são sedativos, calmantes e relaxantes. De acordo com Price (2006), Davis (1996), Lavabre (2005), Silva (1998), Schotten e Correa (2010), Andrei; Peres e Comume, (2005) são eles:

Abeto: (Abies alba Mill.), suas propriedades terapêuticas e medicinais são afrodisíaco, relaxante, calmante, antisséptico, diurético, antiespasmódico e expectorante usados também para a libido.

- Anis: (Pimpinella anisum L), suas propriedades terapêuticas e medicinais são digestivos, expectorantes utilizados pra dispepsia nervosa, enxaquecas de origem digestiva pelo seu poder estimulante.

- Alcaravia: (Carum carvi L.), suas propriedades terapêuticas e medicinais são diurético e estomáquico, utilizados para cansaço mental e tensão muscular.

- Bergamota: (Citrus bergamia), suas propriedades terapêuticas e medicinais são antisséptico, analgésico, digestivo e bactericida, são utilizados para combater o estresse pelos seus efeitos sedativos e energizante.

- Camomila-romana: (Anthemis nobilis), suas propriedades terapêuticas e medicinais são sedativo, relaxante, antisséptico e estomáquico, usados para ansiedade, depressão e irritabilidade.

- Cedro: (Juniperus virginiana L.), suas propriedades terapêuticas e medicinais são sedativo, relaxante, adstringente, diurético, expectorante, repelente de insetos usados para ansiedade e estresse.

- Cipestre: (Cupressus sempervirens L.), suas propriedades terapêuticas e medicinais são restaurador dos nervos e sedativo, além de ser adstringente, antisséptico e cicatrizante usados para irritabilidade e nervosismo.

- Erva-cidreira (lemongrass): (Cybopogon citratu), suas propriedades terapêuticas e medicinais são antisséptico, adstringente, bactericida, regulador, diuréticos e sedativos, usados para o nervosismo.

- Gerânio: (Pelargonium graveolens), suas propriedades terapêuticas e medicinais são adstringente, cicatrizante, antisséptico e diurético. Indicados nos casos de tensão nervosa, como consegue estimular o córtex supra-renal, aonde produz os hormônios é um excelente equilibrador do sistema nervoso.

- Lavanda: (Lavandula officinalis ou Lavandula angustifólia), suas propriedades terapêuticas e medicinais são analgésico, antisséptico, antibiótico, antidepressivo, bactericida, sedativo, cicatrizante. São utilizados para o estresse, pois têm seu efeito sedativo no sistema nervoso central e auxilia no relaxamento ocasionando o equilíbrio.

- Laranja amarga: (Citrus aurantium), suas propriedades terapêuticas e medicinais são calmante, sedativo, antiespasmódico, tônico usados para depressão, medo e irritação.

- Limão: (Citrus medica L.), suas propriedades terapêuticas e medicinais são calmante, antidepressivo, sedativo e auxilia na concentração, além de ser antisséptico e repelente de insetos.

- Manjericão: (Ocimum basilicum L.), suas propriedades terapêuticas e medicinais são tônico do sistema nervoso, sedativo, antisséptico, diurético, expectorante, usados para a ansiedade.

- Manjerona: (Origanum manjerona L.), suas propriedades terapêuticas e medicinais são relaxante, sedativo, expectorante, estomáquico, analgésico e bactericida usados para tensão nervosa, enxaquecas, depressão, angústia, e insônia.

- Melissa: (Melissa officinallis L.), suas propriedades terapêuticas e medicinais são antidepressivo, sedativo, antisséptico, bactericida, antiespasmódico usados para depressão e ansiedade.

- Néroli: (Citrus amara), suas propriedades terapêuticas e medicinais são calmante, relaxante, antidepressivo e afrodisíaco usados para o estresse.

- Olíbano: (Boswellia carterii Birdw), suas propriedades terapêuticas e medicinais são antisséptico, anti-inflamatório, adstringente, coagulante (ferimentos) e vasodilatador usados para a tensão.

- Pinheiro-silvestre: (Pinus sylvestris L.), suas propriedades terapêuticas e medicinais são relaxante, confortante, antisséptico, bactericida, descongestionante e expectorante usados para agitação e nervosismo.

- Petitgrain: (Citrus auramantium), suas propriedades terapêuticas e medicinais são antiespasmódico, antisséptico, digestivo e estimulante da memória, usados para ansiedade e tensão nervosa.

- Rosa-marroquina: (Rosa centifólia L.), suas propriedades terapêuticas e medicinais são antidepressivo, ajuda na concentração, restaura 
a confiança, afrodisíaco, antisséptico, adstringente, tônico, regenerador celular e bactericida usados para fadiga, tristeza, tensão nervosa e depressão.

- Sândalo: (Santatulum álbum L.), suas propriedades terapêuticas e medicinais são calmante, afrodisíaco, antisséptico, antiespasmódico, anti-inflamatório, diurético, usados para depressão, medo e insônia.

- Sálvia-esclaréia: (Salvia sclarea L.), suas propriedades terapêuticas e medicinais são antidepressivo, afrodisíaco, sedativo, antisséptico, antiespasmódico, digestivo, bactericida e regenerador celular, usados para irritabilidade, tensão, cansaço, histeria.

- Tangerina: (Citrus nobilis loureiro), suas propriedades terapêuticas e medicinais são depressão, esgotamento nervoso, é utilizado como antidepressivos, sedativos e relaxantes.

- Tomilho: (Thymus vulgaris L.), suas propriedades terapêuticas e medicinais são antisséptico, antiespasmódico, cicatrizante e antidepressivo usados para o estresse.

- Zimbro: (Juniperus communis L.), suas propriedades terapêuticas e medicinais são analgésico, expectorante, anti-inflamatório e antisséptico, usados para o fortalecimento da memória.

- Verbena-limão: (Lippia citridora HBK.), suas propriedades terapêuticas e medicinais são antisséptico, digestivo, calmantes em pequenas doses, regulador do sistema neurovegetativo, sedativo usados para excesso de tensão e nervosismo.

- Ylang-ylang: (Cananga odorata), suas propriedades terapêuticas e medicinais são antiespasmódico, sedativo, calmante, animador. É indicado para depressão, taquicardia e frigidez, possui o poder afrodisíaco e é um bom relaxante para as tensões nervosas.

\section{Conclusão}

O modelo biomédico tradicional vem buscando alternativas para não tornar o atendimento fragmentado, isso é possível de se analisar visto as ações de promoção da saúde, que possuem como base a integralidade, a atenção ao usuário, à compreensão de um todo.

Os profissionais necessitam buscar na assistência integral, ter compreensão do processo saúde-doença, ter empatia, solidariedade e respeito com o próximo, não tornar esse tratamento apenas como um número, é dar atenção necessária, é fazer a humanização em saúde.

Os cuidados com o indivíduo são necessários para o melhor enfrentamento da patologia do estresse, várias alternativas são possíveis para promover um bem estar e consequentemente uma melhor qualidade de vida.

Uma das alternativas é a utilização de terapias complementares, que já possuem uma portaria no Brasil regularizando o seu uso nas unidades básicas de saúde, no entanto, o que se vê é a sua não utilização, visto que alguns profissionais desacreditam da sua funcionalidade e muitas vezes também não possuem conhecimentos suficientes para a sua aplicação.

A aromaterapia é uma terapia que utiliza concentrados voláteis, que são os óleos essenciais, são oriundos da natureza e fornecem todo o equilíbrio necessário para as pessoas que possuem a patologia do estresse, pois atuam no equilíbrio biopsicossocial, nas dimensões físicas, mentais e espirituais.

Essas terapias são verdadeiros coadjuvantes nos tratamentos do modelo biomédico tradicional, pois há um verdadeiro estudo do ser humano como um ser único e especial. Diversos são os óleos que podem ser utilizados para o estresse, pelos seus efeitos sedativos e calmantes, além das diversidades de maneiras para sua utilização.

O que se preza é sempre ser aplicado por um profissional qualificado, que saiba a sua funcionalidade, maneira e dosagem correta para seu uso. É necessário também que se faça a utilização de óleos essenciais de qualidade para assim poder promover seus efeitos terapêuticos.

Por não ser uma prática comum há ainda pouco uso da mesma, no entanto, é perceptível o seu crescimento, pois é uma terapia não invasiva e proporciona bem estar e relaxamento ao paciente estressado.

\section{Referências}

ALMEIDA, M.; GUTIERREZ, G. Políticas públicas de lazer e qualidade de vida: a contribuição do conceito de cultura para pensar as políticas de lazer. In: VILARTA, Roberto. Qualidade de vida e políticas públicas: saúde, lazer e atividade física. Campinas: IPES, 2004a. p. 67-84.

ALVES, S.; SILVEIRA, C.; AMARAL, F. Manual Ténico WNF: Saúde e Beleza. 6. ed. São Paulo, 2012.

ANDREI, P.; PERES, A.; COMUNE, D. Aromaterapia e suas aplicações. CADERNOS, São Paulo, v. 11, n. 4, p. $57-$ 68, out./dez. 2005.

BERMEJO, J. C. Humanizar a saúde: cuidado, relações e valores. Petrópolis: Vozes, 2008.

BONTEMPO, M. Iniciação à medicina holística. São Paulo: Nova Era, 2001.

BRASIL. Ministério da Saúde. In: CONFERÊNCIA NACIONAL DE SAÚDE, 8., 1986, Brasília. Anais... Brasília: Ministério da Saúde, 1986.

BUSS, P. Promoção da saúde e qualidade de vida. Ciência e Saúde Coletiva, v. 5, n. 1, p. 163-177, 2000.

CZERESNIA, D. Promoção de saúde: conceitos, reflexões, tendências. Rio de Janeiro: Fiocruz, 2003.

DAVIS, P. Aromaterapia. São Paulo: M. Fontes, 1996.

DONAHUE, P. M. Nursing, the finest art: an illustrated history. St. Louis: the C. V. Mosby Company, 1985.

KELLER, E. Guia completo de aromaterapia: cura e 
transformação através das essências e dos óleos aromáticos. 12. ed. São Paulo: Pensamento, 2009.

LASZLO, Fabian. História do uso dos óleos essenciais. Belo Horizonte. 2013. Disponível em: <http://www.laszlo. ind.br/default.asp?pagina=historia $>$. Acesso em: 28 abr. 2013.

LAVABRE, M. Aromaterapia: a cura pelos óleos essenciais. 6. ed. Rio de Janeiro: Nova Era, 2005.

LIMA, P. M.; OLIVEIRA, A. C. M. Relação profissionalpaciente: a busca pela humanização nos serviços de saúde. Revista Fluminense de Odontologia, v.1, n. 371, 2012.

LIPP, M. E. N. Estresse emocional: a contribuição de estressores internos e externos. Rev. Psiq. Clín. v. 28, n. 6 , p. 347-349, 2001. Disponível em: <http://urutu.honet.usp. br/ipq/revista/vol28/n6/artigos/art347.htm>. Acesso em: 07 jun. 2013.

MASCARENHAS, C. V. Promoção da saúde: representações sociais de acadêmicos dos cursos de graduação na área da saúde. 2005. ... F. Dissertação (Mestrado em Saúde Pública) - Universidade Federal de Santa Catarina, Florianópolis, 2005.

MAUL, A. A.; WASICKY, R.; BACCHI, E. M. Extração por fluido supercrítico. Rev. bras. farmacogn. v. 5, n. 2, p. 185-200, 1996. Disponível em: <http://dx.doi.org/10.1590/ S0102-695X1996000200006>. Acesso em: 20 jan. 2013.

PRICE, S. Aromaterapia e as emoções. 2. ed. Rio de Janeiro: Bertrand Brasil, 2006.

SADIR, M. A.; BIGNOTTO, M. M.; LIPP, M. E. N. Stress e qualidade de vida: influência de algumas variáveis pessoais. Padeia, v. 20, n. 45, p. 73-81, jan./abr. 2010.

SANTOS, B. S. Um discurso sobre as ciências. Porto: Afrontamento, 1987.

SCHOTTEN, L. A.; CÔRREA, B. M. Aromaterapia na saúde e na beleza: desenvolvimento de um manual prático. Balneário Camboriú: UNIVALI, 2010.

SILVA, A. R. de. Tudo sobre Aromaterapia: como usá-la para melhorar sua saúde física, emocional e financeira. 2 . ed. São Paulo: Roka, 1998.

SIMÕES, C. M. O.; SPTIZER, V. Óleos essenciais. Porto Alegre: Florianópolis: UFRGS/UFSC, 1999.

SIQUEIRA, M. M. M.; PADOVAM, V. A. R. Bases teóricas de bem-estar subjetivo, bem-estar psicológico e bem-estar no trabalho. Psicologia: Teoria e Pesquisa, v. 24, n. 2, p. 201-209, 2008. Disponível em: <http://www.scielo.br/pdf/ ptp/v24n2/09.pdf > . Acesso em: 01 nov. 2012.

TROVO, M. M.; SILVA, M. J. P. da; LEAO, E. R. Terapias alternativas/complementares no ensino público e privado: análise do conhecimento dos acadêmicos de enfermagem. Rev. Latino-Am. Enfermagem. Ribeirão Preto, v. 11, n. 4, ago. 2003. Disponível em: <http://www.scielo.br/pdf/rlae/ v11n4/v11n4a11.pdf >. Acesso em: 13 mar. 2012.

TSUCHIYA, K. K.; NASCIMENTO, M. J. P. Terapias complementares: uma proposta para a atuação do enfermeiro. Rev Enferm UNISA, São Paulo, v. 3, n. 37, p. 37-42, 2002. 